\title{
Generation of Xylose-Fermenting Saccharomyces Cerevisiae by Protein-Engineering
}

\author{
Seiya Watanabe and Keisuke Makino \\ Ehime University \\ Kyoto University \\ Japan
}

\section{Introduction}

The utilization of ethanol produced from plant biomass (so-called "bioethanol"), which is derived from the fixation of atmospheric $\mathrm{CO}_{2}$, as an industrial carbon source and car fuel is one of the most important research issues for the realization of a sustainable global environment. Currently, bioethanol is produced mainly from agricultural crop biomass, which, however, compete with food and animal feed. Alternatively, "lignocellulosic biomass", such as woods and agricultural residues, is an attractive feedstock, and consists of cellulose, hemicellulose, and lignin. In agricultural crops, corn for example, starch, consisting of cellulose (hexose polymers), accounts for $70 \%$ of the mass, and its biological fermentation is easy. On the other hand, in lignocellulosic biomass, hemicellulose, accounting for $30 \%$ of the mass, is composed of pentoses as well as hexoses such as xylose (and L-arabinose), which cannot be fermented by natural microorganisms.
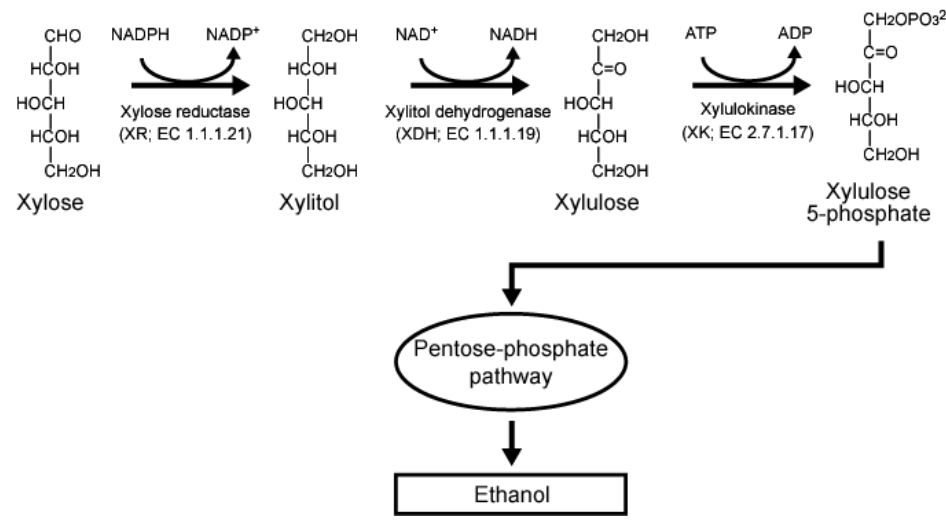

Fig. 1. Xylose metabolism in recombinant S. cerevisiae.

Yeasts, in particular, Sacharomyces cerevisiae have long been used for production of alcoholic beverages such as wine, beer and Japanese "sake", but the native strains also cannot ferment 
xylose as a carbon source. On the other hand, S. cerevisiae transforming with genes encoding to xylose reductase (XR; EC 1.1.1.21) and xylitol dehydrogenase (XDH; EC 1.1.1.9) (mainly from inherently xylose-metabolizing yeast, Pichia stipitis: PsXR and PsXDH) acquires the ability to ferment xylose to ethanol (Fig. 1), whereas produce the excretion of xylitol without the addition of a co-metabolizable carbon source. This is probably caused by several combined factors, and in particular, an intercellular redox imbalance due to a different coenzyme specificity of XR (with NADPH-preference) and $\mathrm{XDH}$ (with strict $\mathrm{NAD}^{+}-$ dependence) has been thought to be one of the main factors (Jeffries \& Jin, 2004). Therefore, generation of novel XR or XDH mutants with modified coenzyme specificity by proteinengineering approach can solve this bottle neck problem.

\section{Protein-engineering of PsXDH}

$\mathrm{XDH}$ belongs to polyol dehydrogenase (PDH) subfamily in a medium-chain dehydrogenase/reductase (MDR) superfamily (Nordling et al., 2002), in which also contains sorbitol dehydrogenase (SDH; EC 1.1.1.14) and L-arabinitol 4-dehydrogenase from several organisms. Most PDHs catalyze strict $\mathrm{NAD}^{+}(\mathrm{H})$-dependent interconversion between alcohols and their corresponding ketones or aldehydes. As well as other MDR enzymes, the coenzyme-binding mode is followed by a classical "Rossmann-fold", and one zinc atom at the catalytic site is necessary for enzyme activity (referred to as "catalytic zinc") (Fig. 2). Furthermore, some possess an additional second zinc atom, which is known as a "structural zinc", although its role has not yet been clarified.

\subsection{Modification of coenzyme specificity toward NADP ${ }^{+}$}

\subsubsection{Strategy of mutant design}

Since $\mathrm{NAD}^{+}(\mathrm{H})$ only differs from $\mathrm{NADP}^{+}(\mathrm{H})$ in the phosphate group esterified at 2 -position of adenosine ribose, a limited number of amino acid residues interacting with these portions are the first candidates for protein engineering using site-directed mutagenesis. Most of these studies are Rossmann-fold type oxidoreductases, and "landmark" amino acid residues have already been proposed for the discrimination between $\operatorname{NAD}^{+}(\mathrm{H})$ and $\operatorname{NADP}^{+}(\mathrm{H})$ (Baker et al., 1992).

Generally, subunit structures in the MDR superfamily are comprised of two domains, namely a "coenzyme binding domain" within the intermediate segment and a "catalytic domain" consisting of N- and C-terminal segments (Fig. 2). The former possesses a similar $\beta$ - $\alpha-\beta$ motif, centred around a highly conserved Gly-X-Gly-X-X-Gly sequence (where $X$ is any amino acid; positions 9 11 in Table 1), in which several specific amino acid residues play a important role to discriminate between $\operatorname{NAD}^{+}(\mathrm{H})$ and $\mathrm{NADP}^{+}(\mathrm{H})$. The primary determinant of $\mathrm{NAD}^{+}(\mathrm{H})$ specificity is the presence of an aspartate residue which forms double-hydrogen bonds to both the 2'- and 3'-hydroxyl groups in the ribosyl moiety of $\mathrm{NAD}^{+}(\mathrm{H})$, and induces negative electrostatic potential to the binding site. Commonly, this residue in $\mathrm{NADP}^{+}(\mathrm{H})$-dependent dehydrogenases is replaced by a smaller and uncharged residue such as glycine, alanine and serine, accompanied by the concurrent presence of an arginine residue that forms a positive-binding pocket for the 2 '-phosphate group of $\mathrm{NADP}^{+}(\mathrm{H})$. 


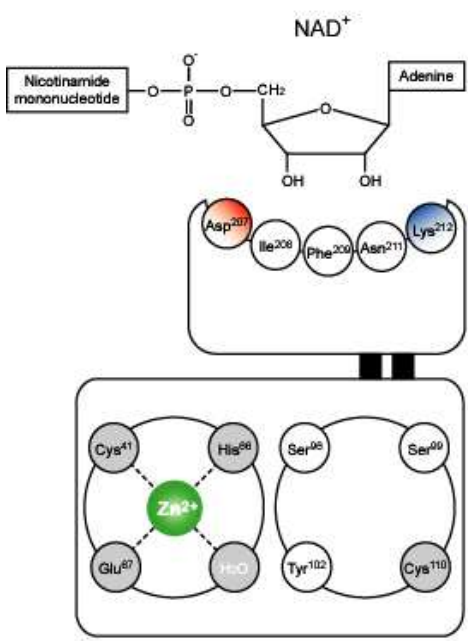

P. stipitis XDH

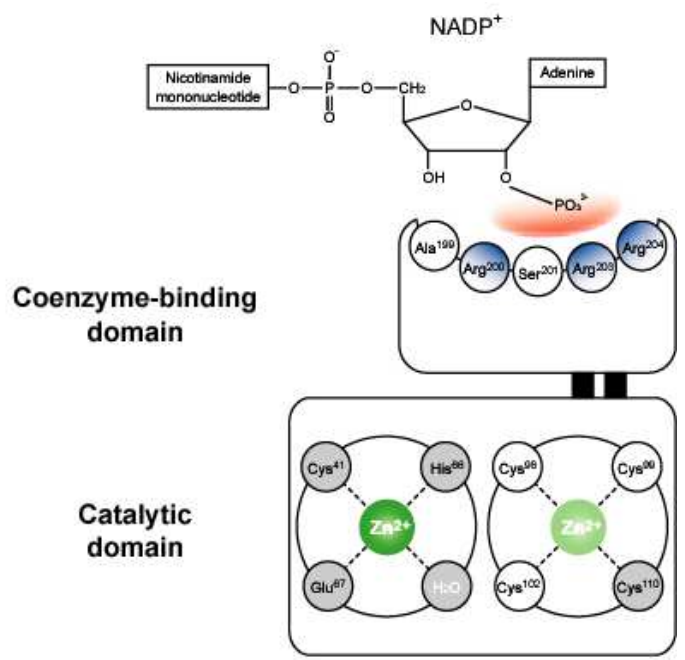

B. argentifolii SDH

Colors of red and blue indicate positive- and negative-charge, respectively.

Dark- and light-green zinc atoms correspond to catalytic and structural zinc, respectively.

The gray-colored ligands are conserved between the two enzymes.

Fig. 2. Schematic diagram of PsXDH and BaSDH structures.

Bemisia argentifolii (whitefly) $\mathrm{SDH}(\mathrm{BaSDH})$ is the only $\mathrm{NADP}^{+}(\mathrm{H})$-dependent enzyme among the characterized PDHs (Banfield et al., 2001). Although the crystal structure of $\mathrm{BaSDH}_{-\mathrm{NADP}}{ }^{+}$complex has not yet been resolved, a phosphate ion from the crystallization buffer is found adjacent to Ala199, Arg200 and Arg204, in the apo-form structure (Fig. 1). The Ala ${ }^{199}-\mathrm{Arg}^{200}$ is obviously homologous to Asp ${ }^{207-I l e}{ }^{208}$ in PsXDH (positions 12 and 13 in Table 1) as described above. These aspartate and hydrophobic residues are conserved completely among other $\mathrm{NAD}^{+}(\mathrm{H})$-dependent PDHs.

\subsubsection{D207A//208R mutant}

Therefore, D207A (Asp207 $\rightarrow$ Ala), I208R and AR (D207A/I208R) mutants were first constructed, functionally expressed as (His) 6 -tagged enzymes in Escherichia coli and purified by $\mathrm{Ni}^{2+}$-affinity chromatography, together with wild-type (WT) enzyme (Fig. 3) (Watanabe et al., 2005). Single substitutions produced a more positive effect on $\mathrm{NADP}^{+}$kinetics than those of $\mathrm{NAD}^{+}$; their $k_{\text {cat }} / K_{\mathrm{m}}{ }^{\mathrm{NADP}}$ values showed an approximately $5 \sim 48$-fold increase (Fig. 4). However, the mutant enzymes still preferred $\mathrm{NAD}^{+}$to $\mathrm{NADP}^{+}$. Double mutation, $\mathrm{AR}$, led to a moderate increase of $k_{\text {cat }} / K_{\mathrm{m}} \mathrm{NADP}$ compared to single mutations. In particular, there was a complete synergistic effect in the AR mutant; the increase in $k_{\text {cat }} / K_{\mathrm{m}}$ for AR was 250 -fold, the same as the product of the ratios of the increase in $k_{\text {cat }} / K_{\mathrm{m}}$ for D207A and for I208R. On the other hand, $k_{\text {cat }} / K_{\mathrm{m}}{ }^{\mathrm{NAD}}$ values did not significantly change in the mutants. Overall, the double mutants improved the catalysis for NADP ${ }^{+}$, although $k_{\text {cat }} / K_{\mathrm{m}} \mathrm{NADP}^{\mathrm{N}}\left(149 \mathrm{~min}^{-1} \mathrm{mM}^{-1}\right)$ did not reach the $k_{\text {cat }} / K_{\mathrm{m}}{ }^{\mathrm{NAD}}$ of WT $\left(2,760 \mathrm{~min}^{-1} \mathrm{mM}^{-1}\right)$. 


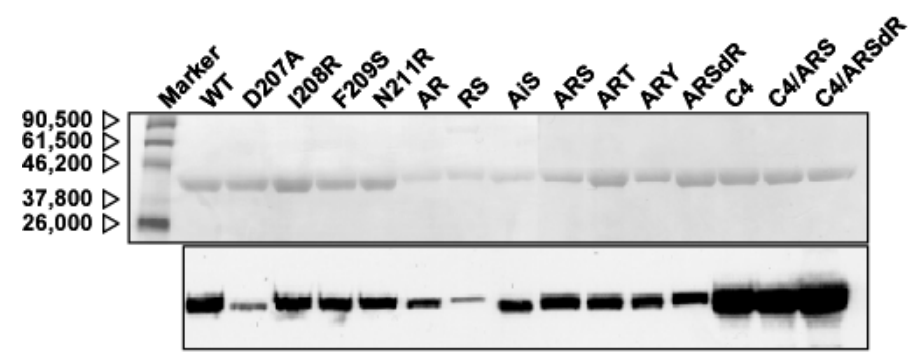

Fig. 3. Expression and purification of recombinant PsXDHs.

SDS-PAGE of purified enzyme (upper panel); intercellular expression level in E. coli, estimated by Western blot analysis (lower panel).

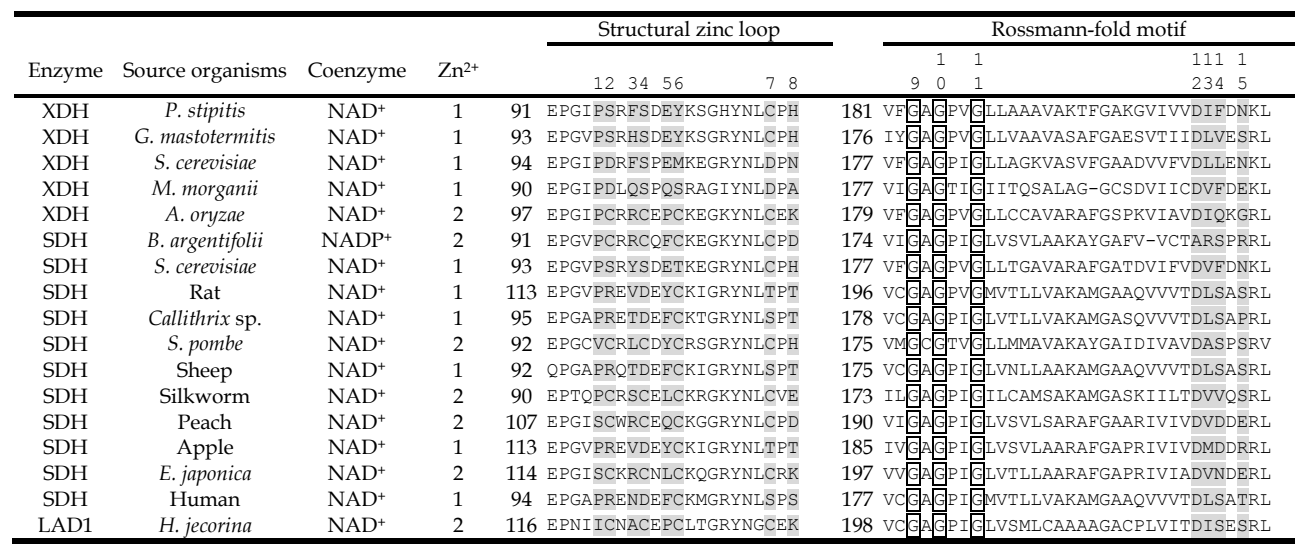

Table 1. Partial sequence alignment of the PDH subfamily enzymes including PsXDH.

\subsubsection{D207A/I208R/F209S mutant}

It is difficult to judge whether the position of 209 should be involved in the mutation sites, because there is homologous Ser residue regardless of $\mathrm{NAD}^{+}(\mathrm{H})$ - and $\mathrm{NADP}^{+}(\mathrm{H})$-dependent enzyme(s) (position 14 in Table 1). In fact, the homologous position has not been targeted by site-directed mutagenesis for the reversal of coenzyme specificity in other $\mathrm{NAD}(\mathrm{P})^{+}-$ dependent dehydrogenases. Very surprisingly, an additional introduction of F209S mutation into AR mutant leaded dramatic striking effects in kinetic constants for both NAD ${ }^{+}$ and $\mathrm{NADP}^{+}$(Fig. 4) The $k_{\text {cat }} / K_{\mathrm{m}} \mathrm{NAD}^{\mathrm{N}}$ dropped 15 -fold compared to WT by an increase of $K_{\mathrm{m}}$ and a decrease of $k_{\text {cat }}$. On the other hand, $k_{\text {cat }} / K_{\mathrm{m}}$ NADP increased dramatically (up to 4,100fold), caused by a large decrease of $K_{\mathrm{m}}$ value and increase of $k_{\text {cat }}$ value. It is noteworthy that $k_{\text {cat }} / K_{\mathrm{m}} \mathrm{NADP}\left(2,790 \mathrm{~min}^{-1} \mathrm{mM}^{-1}\right)$ was almost identical to that of WT for NAD ${ }^{+}$.

F209S single mutation itself and/or double mutation with D207A or I209R (AiS and RS mutants, respectively) gave no significant effect, compared with ARS mutant. What is important factor(s) for the change of the kinetics constants for $\mathrm{NADP}^{+}$between $\mathrm{AR}$ and ARS? ARY (D207A/I208R/F209Y) and ART (D207A/I208R/F209T) mutants were constructed for analysis of the volumetric effect of hydroxyl side chain (Fig. 4). $k_{\text {cat }} / K_{\mathrm{m}}{ }^{N A D P}$ 
value of ART mutant was almost the same as that of ARS. Furthermore, the $k_{\text {cat }}$ values for $\mathrm{NADP}^{+}$was reduced by an order of magnitude from ARS $>\mathrm{ART}>\mathrm{AR}>\mathrm{ARY}$ in agreement with the order of the side-chain volume. These results indicate that not only the hydroxyl group but also the relatively small volume group is required for the side chain of the residue at this position to make hydrogen bonds with amino moiety(s) of the side chain of neighbour amino acid residues (probably Arg 208 and Lys ${ }^{212}$ in the ARS mutant) similar to BaSDH. Rosell et al. (2003) reported a study about several $\mathrm{NAD}^{+}(\mathrm{H})$-dependent mutants of a vertebrate $\mathrm{NADP}^{+}(\mathrm{H})$-dependent alcohol dehydrogenase $(\mathrm{ADH})$ isozyme 8 . For complete reversal of the coenzyme specificity toward $\operatorname{NAD}^{+}(\mathrm{H})$, substitution of three amino acid residues at homologous positions of Asp207-Ile208-Phe ${ }^{209}$ in PsXDH was necessary. These results indicate that, in some cases of dehydrogenase, an amino acid residue close to the "landmark" amino acid residues would also be effective for coenzyme recognition.

\subsubsection{D207A/I208R/F209S/N211R mutant}

Although ARS mutant shows a satisfied ratio of $\mathrm{NADP}^{+} / \mathrm{NAD}^{+}$preference in terms of $k_{\text {cat }} / K_{\mathrm{m}}, 15.4$, the thermostability decreased significantly, as described below. BaSDH possess Arg203, while the basic residue is only rarely seen among $\mathrm{NAD}^{+}(\mathrm{H})-\mathrm{PDH}$ involving PsXDH (position 15 in Table 1). A single mutation of N211R gave no effect on coenzyme specificity (Fig. 4). On the other hand, introduction of this mutation into ARS mutant (ARSdR) produced about a 2 -fold decrease in the $k_{\text {cat }} / K_{\mathrm{m}} \mathrm{NAD}$ value mostly because of a dramatic decrease of $K_{\mathrm{m}}$ value compared to WT, whereas no additional change in the kinetics constant for $\mathrm{NADP}^{+}$was observed. Finally, this best quadruple mutant showed over 4,500fold higher $k_{\text {cat }} / K_{\mathrm{m}}{ }^{\mathrm{NADP}}$ and over 32 -fold lower $k_{\text {cat }} / K_{\mathrm{m}}{ }^{\mathrm{NAD}}$ values, compared with WT; complete reversal coenzyme specificity was achieved. Furthermore, the N211R mutation compensated thermolability in ARS mutant (see below).

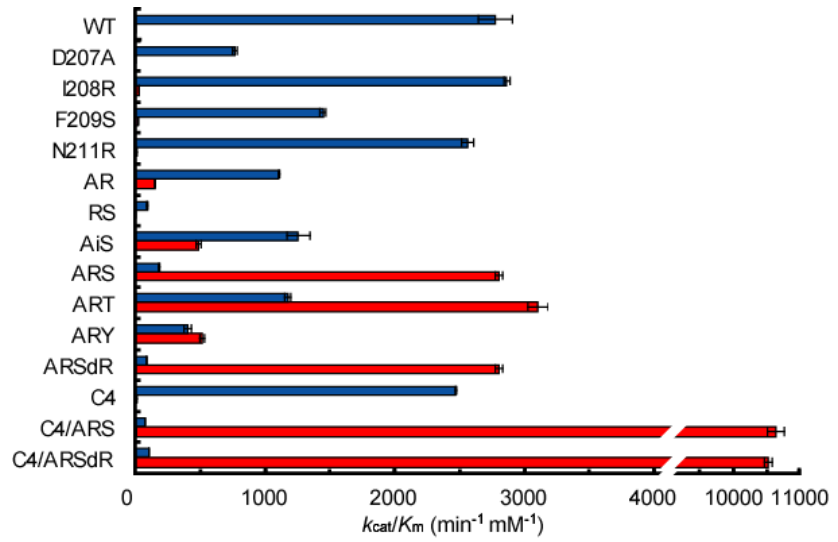

Fig. 4. Catalytic efficiency $\left(k_{\text {cat }} / K_{\mathrm{m}}\right)$ with $\mathrm{NAD}(\mathrm{P})^{+}$for WT and mutant PsXDH.

\subsubsection{Importance of reference enzyme(s)}

Metzger \& Hollenberg (1995) also attempted to identify a set of amino acid residues in $\mathrm{PsXDH}$ for specificity toward $\mathrm{NAD}^{+}$. They introduced the potential $\mathrm{NADP}^{+}(\mathrm{H})$-recognition 
sequence of E. coli glutathione reductase (no homology with PsXDH) and thermophilic $\mathrm{ADH}(\sim 30 \%$ homology) into the homologous sequence in PsXDH, Asp207-Ile208-Phe209Asp210-Asn ${ }^{211}$-Lys ${ }^{212}$. Among several mutants constructed, D207V/I208R/F209S/D210H mutant, which is very similar to the D207A/I208R/F209S (ARS) mutant, was not expressed in the host cell, in contrast of this study (see Fig. 3). Generally, there are a few sequence homologies among MDRs at the coenzyme recognition site except some specific residues, although the conformational fold is conserved. BaSDH, a reference enzyme in this study, is phylogenetically closer to PsXDH than glutathione reductase and/or ADH, supposing that the step-by-step acquirement of activity with $\mathrm{NADP}^{+}$in $\mathrm{PsXDH}$ seems to mimic the natural evolutional process.

\subsection{Thermostabilization}

Protein stability is one of most important factors for application of industrial enzymes. Although $\mathrm{XDH}$ itself is not directly utilized for ethanol production, it is well known that there is significant relationship between the stability and intercellular expression level. Since there have been no reports about the $\mathrm{XDH}$ of thermophilic microorganisms, we cannot undertake site-directed mutagenesis based on the structural comparison of thermophilic $\mathrm{XDH}$ and mesophilic PsXDH and/or the random mutagenesis method. Alternative method for the thermostabilization should be developed.

\subsubsection{Strategy of mutant design}

In the BaSDH (Banfield et al., 2001), structural zinc atom is coordinated with four cysteine residues (Cys ${ }^{96}, \mathrm{Cys}^{99}, \mathrm{Cys}^{102}$ and $\mathrm{Cys}^{110}$ ) as well as many other structural zinc-containing ADHs (a pattern of C-C-C-C) (Fig. 1 and positions 2, 4, 6 and 7 in Table 1). There are some substitution patterns of these four cysteines in the PDHs. Among them, enzymes with the pattern of D-S-M-D, R-D-C-S, R-D-C-T have been shown to have no structural zinc. These analyses suggested that four fully conserved cysteine residues are necessary for binding to the structural zinc atom, and that PsXDH having a pattern of S-S-Y-C, has no structural zinc atom. On the other words, it is likely that the substitutions of Ser 96 , Ser ${ }^{99}$ and Tyr ${ }^{102}$ by cysteine residues may increase the thermostability due to introduction of the structural zinc; so-called C4 mutant (S96C/S99C/Y102C) (Watanabe et al., 2005).

\subsubsection{Introduction of structural zinc}

Atomic absorption spectroscopy analysis revealed that the WT and C4 mutant contain 1.0 and $1.9 \mathrm{~mol} \mathrm{zinc} / \mathrm{mol}$ subunit. Since the putative binding site for the catalytic zinc is conserved completely in PsXDHs (Cys ${ }^{41}$, His ${ }^{66}$ and $\mathrm{Glu}^{67}$ ), compared to other MDRs, this result should be interpreted as the acquirement of an additional zinc in $\mathrm{C} 4$ mutant. The $\mathrm{C} 4$ mutant displayed almost the same $k_{\text {cat }} / K_{\mathrm{m}}{ }^{\mathrm{NAD}}$ value; strict $\mathrm{NAD}^{+}$-dependent enzyme (Fig. 4). The thermostability of the $\mathrm{C} 4$ mutant was estimated from the $T_{\mathrm{m}}$ value by circular dichroism (CD) measurements (left panel in Fig. 5). The introduction of the structural zinc atom increased the thermostability of the $\mathrm{C} 4$ mutant $\left(4.5^{\circ} \mathrm{C}\right.$ increase of the $T_{\mathrm{m}}$ value compared to WT). Similar results were obtained by heat treatment of the enzyme; the enzyme activity of WT decreased to $15 \%$ after incubation for $10 \mathrm{~min}$ at $40{ }^{\circ} \mathrm{C}$, whereas no inactivation of the $\mathrm{C} 4$ mutant was detected by the same treatment (right panel in Fig. 5). The level of translational expression of the $\mathrm{C} 4$ mutant was approximately 3 -fold higher than that of WT (Fig. 3), suggesting that the stability of the C4 mutant was also increased in vivo. 
In cases of human ADHs (Jeloková et al., 1994) and bacterial phenylacetaldehyde reductase (Wang et al., 1999), it is impossible to remove structural zinc without loss of stable folding or enzyme activity. On the other hand, when ADHs from yeast (Magonet et al., 1992) and thermophilic archaea (Ammendola et al, 1992) are incubated with a chelating reagent, the structural zinc atom is selectively removed with no effect on the catalytic zinc or loss of enzyme activity, while the enzyme becomes very sensitive to treatment with heat and/or denaturant. These different results may reflect the role change of the structural zinc in the enzyme during evolution. Ancestral MDR enzyme had probably possessed this zinc by coordination of four cysteine ligands, which is absolutely necessary for both stability and enzyme activity (such as human $\mathrm{ADH}$ ). Eventually, the role had been limited for maintaining the stability (such as yeast $\mathrm{ADH}$ ), and subsequently no significant contribution, which leaded a loss of the structural zinc and random substitution of four cysteine ligands (such as PsXDH). Therefore, C4 mutation of PsXDH also seems to mimic the natural evolutional process "reversely", as well as modification of coenzyme specificity toward $\mathrm{NADP}^{+}$.

In case of random mutagenesis method, single (or double) mutation with moderate effects on thermostability are first isolated, and these combination and/or further randomization are subsequently carried out. However, C4 mutation don't have to be generated by this method, because single and/or double mutations of S96C, S99C and Y102C give no effect to stabilize PsXDH. Since it is easy to identify whether a MDR enzyme contains a structural zinc atom by simple analysis of the amino acid sequence alignment, this novel strategy for protein stabilization would be applicable for other MDRs that contain no structural zinc atom natively.

\subsubsection{Thermostabilization of $\mathrm{NADP}^{+-}$dependent mutants}

Modification of coenzyme specificity toward NADP+ in PsXDH resulted in a significant loss of thermostability (Fig. 5), which is also found in other several dehydrogenases/reductases. Therefore, the C4 mutation was combined with each ARS and ARSdR mutation, to construct the C4/ARS and C4/ARSdR mutant, respectively (Watanabe et al., 2005). Their translational expression levels in E. coli were almost the same as the C4 mutant (Fig. 3), estimating that the stability in vivo might increase compared to their parent enzymes, ARS and ARSdR. In fact, their $T_{\mathrm{m}}$ values were almost the same as that of the $\mathrm{C} 4$ mutant and, in particular, C4/ARS was dramatically stabilized by improving the $T_{\mathrm{m}}$ of $7.7^{\circ} \mathrm{C}$ compared to ARS (left panel in Fig. 5). Heat treatment of the enzymes provided similar results; after incubation for $10 \mathrm{~min}$ at $45^{\circ} \mathrm{C}, \mathrm{C} 4 / \mathrm{ARS}$ and C4/ARSdR maintained about half the activity, whereas no enzyme activity of ARS and ARSdR mutants was detected by the same treatment (right panel in Fig. 5). The zinc content of C4/ARS and C4/ ARSdR mutants was 1.69 and 1.78 mol zinc/mol subunit, respectively, suggesting that their increased thermostability was due to the structural zinc atom introduced.

Unexpectedly, C4/ARS and C4/ARSdR mutants showed a further $\sim 4$-fold improved $k_{\text {cat }} / K_{\mathrm{m}}{ }^{\mathrm{NADP}}$ values, mainly caused by an increase in $k_{\text {cat }}{ }^{\mathrm{NADP}}$ values (Fig. 4$)$. Finally, their $k_{\text {cat }} / K_{\mathrm{m}} \mathrm{NADP}$ values reached much higher than the initial $k_{\text {cat }} / K_{\mathrm{m}} \mathrm{NAD}$ value of WT; ratio of $\mathrm{NADP}^{+} / \mathrm{NAD}^{+}$preference in terms of $k_{\text {cat }} / K_{\mathrm{m}}, 142$ and 101 , respectively. 

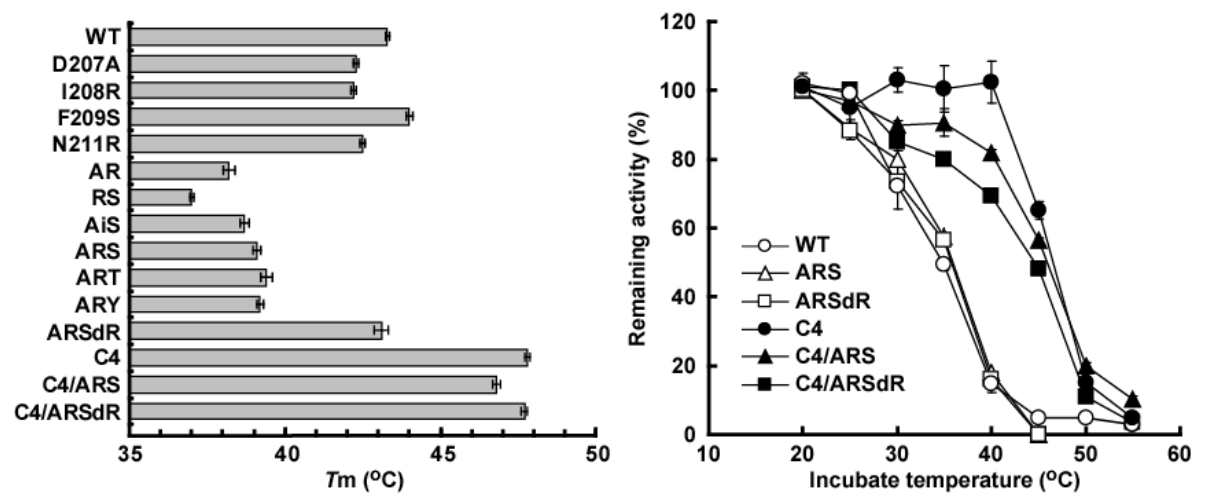

Fig. 5. Comparison of thermostability for WT and mutant PsXDH, estimated by CD analysis (left panel) and heat-inactivation (right panel).

Although protein stabilization generally confers rigidity on the protein and subsequently produces increased ligand affinity, there is no such change in the kinetic constants of C4/ARS and C4/ARSdR mutants. It is noteworthy that the C4 mutation site is separate from ARS/ARSdR sequentially and structurally (Fig. 1 and Table 1). These results suggest the possibility that thermostabilization can enhance the catalytic activity of enzymes, which modified the coenzyme specificity in other dehydrogenases/reductases.

\subsubsection{Optimization of structural zinc-binding loop}

If the hypothesis described in 2.2.2. is similar to evolutional process, the effect might have been also appeared neighbor region of four cysteine ligands, suggesting one possibility that the optimization leads to further stabilize C4 mutant. The structural zinc is bound within a protruding loop from the catalytic domain, whose corresponding amino acid sequence among all PDHs is completely or highly conserved regardless of the existence of the zinc atom; Glu' Gly93, Lys103, Gly105, Tyr107, Asn'108 and Leu109 (numbering for PsXDH). Therefore, among amino acid residues except them, four positions of 95, 98, 101 and 112 in PsXDH C4 mutant (positions 1, 3, 5 and 8 in Table 1) were selected as site-directed mutation, to construct C4/P95S, C4/F98R, C4/E101F and C4/H112D mutants, respectively (Annaluru et al., 2007).

Among them, significant thermostabilization were found only in C4/F98R and C4/E101F mutants, compared with parent $\mathrm{C} 4$ mutant; higher $T_{\mathrm{m}}$ values of $4.2^{\circ} \mathrm{C}$ and $3.0^{\circ} \mathrm{C}$, respectively. Similarly, after incubation for $10 \mathrm{~min}$ at $50^{\circ} \mathrm{C}, \mathrm{C} 4 / \mathrm{F} 98 \mathrm{R}$ and C4/E101F maintained approximately $50 \%$ and $70 \%$ of the activity, whereas only $20 \%$ for C4 mutant. Therefore, based on the results, the C4/F98R/E101F mutant was constructed. Expectedly, the synergic effect of combination of two successive mutations on thermostabilization was observed in this mutant; the $T_{\mathrm{m}}$ value was $2.1^{\circ} \mathrm{C}$ and $3.3^{\circ} \mathrm{C}$ higher than $\mathrm{C} 4 / \mathrm{F} 98 \mathrm{R}$ and C4/E101F, respectively, and approximately $90 \%$ of activity remained after incubation for 10 min at 50 ${ }^{\circ}$. Finally, this quintuple mutation, S96C/S99C/Y102C/F98R/E101F, leaded to dramatically stabilize PsXDH WT by increase of $10.8^{\circ} \mathrm{C}$ in $T_{\mathrm{m}}$.

The region of the structural zinc-binding loop is known to be involved in stabilizing the dimer-dimer interaction. In case of $\mathrm{BaSDH}$, the arginine and phenylalanine residues at the 
homologous positions with $\mathrm{Phe}^{98}$ and Glu ${ }^{101}$ in PsXDH exist and participate in the interface interactions of two identical subunits. Since PsXDH is also homodimeric structure, thermostabilization from C4 to C4/F98R/E101F may be due to enhancement of intersubunit interaction rather than intrasubunit.

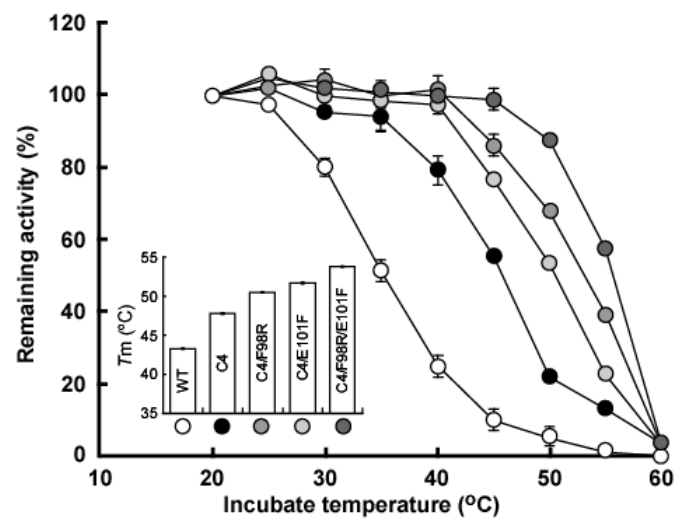

Fig. 6. Heat-inactivation curve of C4-derivative mutant and the $T_{\mathrm{m}}$ (inset).

\section{Protein-engineering of PsXR}

XR belongs to the aldo-keto reductase (AKR) superfamily, which is made up of 14 different families and approximately 120 members (Ellis, 2002). Their three-dimensional structure share a common $(\alpha / \beta)_{8}$ barrel fold, with a highly conserved coenzyme binding pocket at the C-terminus; no Rossmann-fold type binding mode, in contrast of XDH. Although most members of this superfamily show strong dependence on NADPH, a few members including XR (AKR2B5), 3a-hydroxysteroid dehydrogenase (AKR1C9) and 3dehydroecdysone $3 \beta$-reductase (AKR2E1) can utilize both NADH and NADPH. To relax an intercellular redox imbalance between $\mathrm{XR}$ and $\mathrm{XDH}$ in $S$. cerevisiae cells, generation of $\mathrm{XR}$ mutant(s) with modified coenzyme specificity is alternative approach.

\subsection{Modification of coenzyme specificity toward NADH}

\subsubsection{Strategy of mutant design}

NADH-preferring PsXR mutants were designed by different three strategies based on the following observations (Watanabe et al., 2007).

1. In contrast of most XR including PsXR, XR from Candida parapsilosis (CpXR) shows 100fold higher utilization of NADH than NADPH in terms of catalytic efficiency; it possesses a unique arginine residue in the coenzyme-binding pocket instead of Lys 270 in the PsXR (Table 2) (Lee et al., 2003).

2. Several site-directed mutagenetic and crystallographic studies for modifying coenzyme specificity toward NADH, using NADPH-preferring NAD $(\mathrm{P}) \mathrm{H}$-preferring $\mathrm{XR}$ from Candida tenuis (CtXR), were reported (Fig. 7) (Petschacher et al., 2005; Petschacher \& Nidetzky, 2005). This fungal XR shows $\sim 77 \%$ sequential similarity to PsXR. The K274R/N276D mutations lead the highest ratio of NADH/NADPH preference in terms 
of $k_{\text {cat }} / K_{\mathrm{m}}$ among the series of CtXR mutants investigated, and corresponds to K270R/R272D mutations in PsXR.

3. 2,5-Diketo-D-gluconic acid reductase, a member of the AKR superfamily (AKR5C1), also shows inherent NADPH specificity. However, mutations equivalent to K270G and $\mathrm{R} 276 \mathrm{H}$ in PsXR leads to efficient NADH preference (Banta et al., 2002).

\begin{tabular}{|c|c|c|c|c|c|c|c|c|c|}
\hline \multirow{4}{*}{ Enzyme } & \multirow{4}{*}{ Source organisms } & \multirow{4}{*}{$\begin{array}{l}\text { Coenzyme } \\
\text { preference }\end{array}$} & \multicolumn{7}{|c|}{ Sequence } \\
\hline & & & 2 & 2 & 2 & 2 & 2 & 2 & 2 \\
\hline & & & 2 & 2 & 2 & 7 & 7 & 7 & 7 \\
\hline & & & 2 & 3 & 4 & 0 & 1 & 2 & 6 \\
\hline $\mathrm{XR}$ & P. stipitis & NADPH & $\mathrm{V}$ & $\mathrm{E}$ & $\mathrm{L}$ & K & $\mathrm{S}$ & $\mathrm{N}$ & $\mathrm{R}$ \\
\hline $\mathrm{XR}$ & C. tropicalis & NADPH & L & $\mathrm{E}$ & L & K & s & $\mathrm{N}$ & $\mathrm{R}$ \\
\hline $\mathrm{XR}$ & P. guilliermondii & NADPH & V & $\mathrm{E}$ & L & K & s & $\mathrm{N}$ & R \\
\hline $\mathrm{XR}$ & P. tannophilus & NADPH & L & $\mathrm{E}$ & L & K & S & $\mathrm{T}$ & $\mathrm{T}$ \\
\hline $\mathrm{XR}$ & K. lactis & NADPH & L & $\mathrm{E}$ & L & K & s & S & R \\
\hline $\mathrm{XR}$ & A. niger & NADPH & L & $\mathrm{E}$ & L & K & s & $\mathrm{N}$ & R \\
\hline $\mathrm{XR}$ & C. parapsilosis & NADH & L & $E$ & M & K & s & S & R \\
\hline XR & C. tenuis & NADPH & V & $\mathrm{E}$ & M & K & s & L & $\mathrm{R}$ \\
\hline XR(M) & C. tenuis & NADH & V & $\mathrm{E}$ & M & $\mathrm{R}$ & D & L & $\mathrm{R}$ \\
\hline 2,5-DKGRA & Corynebacterium sp. & NADPH & Y & D & L & $\mathrm{K}$ & s & V & $\mathrm{R}$ \\
\hline 2,5-DKGRA(M) & Corynebacterium sp. & NADH & Y & D & L & G & S & V & $\mathrm{R}$ \\
\hline 2,5-DKGRA(M) & Corynebacterium sp. & $\mathrm{NADH}$ & Y & D & L & K & s & $\mathrm{V}$ & $\mathrm{H}$ \\
\hline
\end{tabular}

" $\mathrm{M}$ " is a mutant enzyme.

Table 2. Partial sequence alignment of the AKR superfamily.

\subsubsection{Characterization of mutants}

Specific activities of the recombinant PsXR WT enzyme in the presence of NADH and $\mathrm{NADPH}$ were 7.2 and $15.7 \mathrm{U} \mathrm{mg}^{-1}$, respectively; NADPH-preference specificity. Among several constructed single and/or multiple mutants, the high ratio of NADH/NADPH in $k_{\text {cat }} / K_{\mathrm{m}}$ was found in R276H and K270R/N272D mutants: 2.62 and 7.29, respectively. Their kinetic constants for NADH were almost same as those of WT, although K270R/N272D mutant showed approximately 5 -fold higher $K_{\mathrm{m}}$ value with $\mathrm{NADH}$. On the other hand, the $k_{\text {cat }} / K_{\mathrm{m}}$ NADP values of R276H and K270R/N272D mutants decreased 28-fold and 370-fold, compared with WT, which were mainly due to 40 -fold decrease of $k_{\text {cat }}$ value and 1,120-fold increase $K_{\mathrm{m}}$ value, respectively. When the $\mathrm{R} 276 \mathrm{H}$ mutation was introduced in the K270R/N272D mutant, no further improvement of NADH preference appeared. This may be due to antagonistic effect by the introduction of two arginine residues, which may also account for a similar result found in the corresponding triple mutant of CtXR, K274R/N276D/R280H (Petschacher et al., 2005; Petschacher \& Nidetzky, 2005): the effect of steric hindrance on the 2 '-phosphate group of $\mathrm{NADP}^{+}$, generated by the introduction of the side chain of Arg270, could be strongly reduced when side chain of $\mathrm{Arg}^{276}$ is substituted to the smaller side chain of a histidine.

Surprisingly, the greatest thermostabilization was found in the $\mathrm{R} 276 \mathrm{H}$ single mutant (increase of $8.8^{\circ} \mathrm{C}$ in $T_{\mathrm{m}}$ ). Similar results were obtained by heat treatment of the enzyme: the activity of the WT enzyme decreased to only $4.1 \%$ after incubation for $10 \mathrm{~min}$ at $30{ }^{\circ} \mathrm{C}$, whereas mutants containing the $\mathrm{R} 276 \mathrm{H}$ mutation maintained $92 \%$ of activity after the same treatment. These results were unexpected because, as observed in PsXDH (see above), the modification(s) of coenzyme specificity leads to a significant loss of thermostability. 


\subsection{Modification of coenzyme specificity toward NADPH}

In CtXR, several limited numbers of amino acid residues commonly play a role to bind both to NADH and NADPH; Glu ${ }^{223}$, Lys ${ }^{270}$, Ser271, Asn'272 and Arg276 in PsXR (Fig. 7) (Kavanagh et al., 2002, 2003). Therefore, it is very surprisingly that the substitution of Glu ${ }^{223} \rightarrow$ Ala in PsXR leaded to eliminate NADH-dependent activity completely, although the $k_{\text {cat }} / K_{\mathrm{m}}{ }^{\mathrm{NADPH}}$ value was $\sim 25 \%$ of WT (Khattab et al., 2011). Furthermore, since only Ser 271 is specific for NADPHbinding, the substitution to alanine may change the coenzyme specificity toward NADH over NADPH. However, the additional S271A mutation in E223A mutant compensated the decreased NADPH-dependent activity, and the $k_{\text {cat }} / K_{\mathrm{m}}{ }^{\mathrm{NADPH}}$ value $\left(32.4 \mathrm{~min}^{-1} \mu \mathrm{M}^{-1}\right)$ was almost comparable with that of WT $\left(38.6 \mathrm{~min}^{-1} \mu \mathrm{M}^{-1}\right)$.
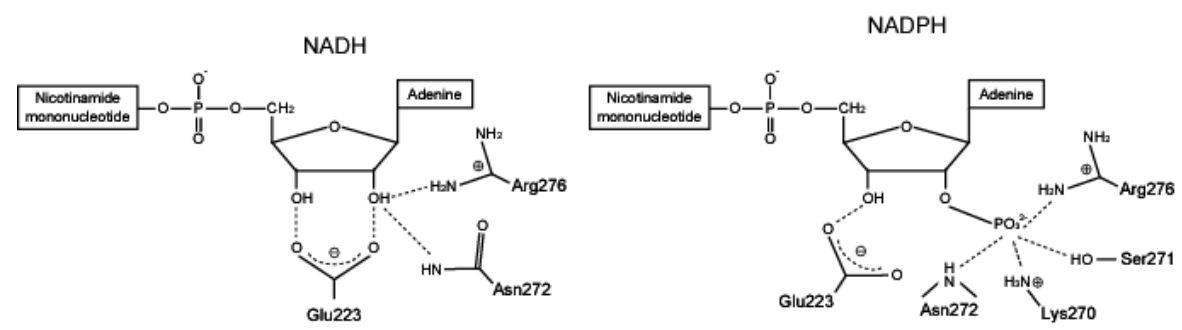

Fig. 7. Schematic diagram of putative interactions between PsXR and NAD $(P) H$.

\section{Xylose-fermentation by S. cerevisiae using mutated XDH and/or XR}

Although the native S. cerevisiae cannot ferment xylose, the S. cerevisiae transformed with the native genes encoding PsXR and PsXDH, a most potent recombinant strain, acquires the ability to ferment xylose to ethanol.

\subsection{Screening of XDH and XR mutants}

Each gene encoding PsXDH WT, ARS, ARSdR, C4, C4/ARS or C4/ARSdR was constitutively expressed in a laboratory S. cerevisiae strain together with PsXR WT gene (Watanabe et al., 2007b), whereas each gene encoding PsXR WT, K270R, R276H or K270R/N272D together with PsXDH WT gene (Watanabe et al., 2007ac); referred to as Y-X (" $X^{\prime \prime}$ is a enzyme name). Fermentation by these recombinant yeasts was started with $5 \mathrm{~g} \mathrm{~L}^{-1}$ glucose and $15 \mathrm{~g} \mathrm{~L}^{-1}$ xylose in a minimal medium. Y-WT produced ethanol at $2.22 \mathrm{~g} \mathrm{~L}^{-1}$ and excluded xylitol at $1.42 \mathrm{~g} \mathrm{~L}^{-1}$. Among the XDH mutants, Y-ARSdR produced the highest amount of ethanol at $2.97 \mathrm{~g} \mathrm{~L}^{-1}$ and excreted the lowest amount of xylitol at $0.16 \mathrm{~g} \mathrm{~L}^{-1}$, whereas among the XR mutants, Y-R276H produced the highest amount of ethanol at $2.30 \mathrm{~g}$ $\mathrm{L}^{-1}$ and excreted the lowest amount of xylitol at $0.97 \mathrm{~g} \mathrm{~L}^{-1}$. These results indicate that these protein-engineering approach are useful for the fermentation of xylose to ethanol using $S$. cerevisiae.

\subsection{Which of modification between XDH and XR is better?}

The fermentation by Y-ARSdR and Y-R276H was further subjected using a bioreactor under the same conditions as the preliminary experiment and compared with that by Y-WT. Y- 
ARSdR produced ethanol at $7.02 \mathrm{~g} \mathrm{~L}^{-1}$ with a yield of $0.46 \mathrm{~g}$ of ethanol $\mathrm{g}^{-1}$ of total consumed sugars, whereas $5.94 \mathrm{~g} \mathrm{~L}^{-1}$ with a yield of $0.43 \mathrm{~g}$ of ethanol $\mathrm{g}^{-1}$ of total consumed sugars for Y-R276H (Fig. 2). When compared with Y-WT, Y-ARSdR and Y-R276H showed $86 \%$ and $52 \%$ decrease of unfavorable xylitol excretion with $41 \%$ and $20 \%$ increased ethanol production, respectively. Measurement of the intracellular coenzymes concentrations that the ratios of $\mathrm{NADH} / \mathrm{NAD}^{+}$and $\mathrm{NADPH} / \mathrm{NADP}^{+}$are more similar to those of strain harboring empty vectors (Y-vector) by an order of magnitude from Y-ARSdR $>$ Y-R276H $>Y$ WT (Fig. 9). These results clearly indicate that utilization of $\mathrm{NADP}^{+}(\mathrm{H})$ by $\mathrm{XDH}$ and $\mathrm{XR}$ gives more positive effect to prevent xylitol accumulation than that of $\mathrm{NAD}^{+}(\mathrm{H})$, due to maintenance of redox balance in yeast cells.
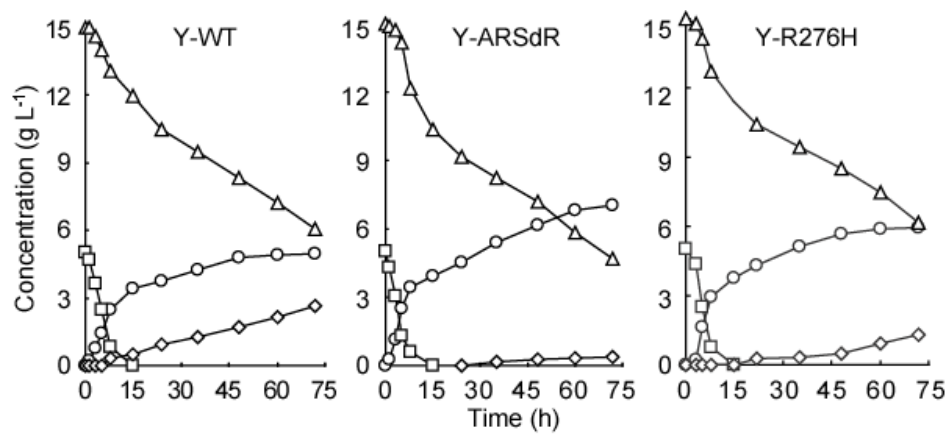

Fig. 8. Xylose fermentation by recombinant S. cerevisiae Y-WT, Y-ARSdR and Y-R276H.

Glucose (square); xylose (triangle); xylitol (rhomboid); ethanol (circle).

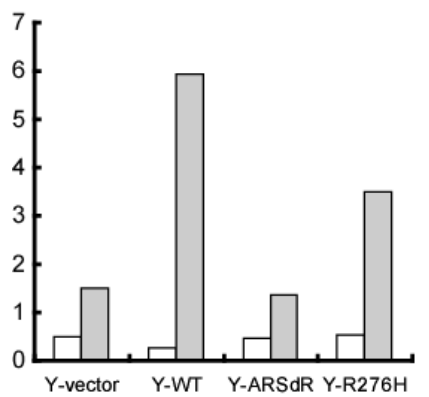

Fig. 9. Ratios of $\mathrm{NADH} / \mathrm{NAD}^{+}$and $\mathrm{NADPH} / \mathrm{NADP}^{+}$in recombinant $S$. cerevisiae.

\subsection{Generation of more applicative S. cerevisiae strain}

It is well known that overexpression of the XKS1 gene encoding xylulokinase (XK) from $S$. cerevisiae $(\mathrm{ScXK})$ is shown to aid xylose utilization, and that native strain can metabolize (ferment) "xylulose". A flocculent S. cerevisiae strain IR-2 was identified as high ability to ferment xylulose; a useful host strain for genetically engineering xylose fermentation (Matsushika et al, 2008ab). Therefore, PsXR, PsXDH (WT or ARSdR mutant) and ScXK genes were integrated on chromosome, and constitutively overexpressed; MA-R4 (vector control) and MA-R5 recombinant strains, respectively (Matsushika et al, 2009). 
On a nutrient-rich medium containing $45 \mathrm{~g} \mathrm{~L}^{-1}$ xylose, MA-R4 and MA-R5 consumed 79\% and $95 \%$ of the xylose at $33 \mathrm{~h}$, respectively (Fig. 10); MA-R5 produced a maximum of $16.0 \mathrm{~g}$ $\mathrm{L}^{-1}$ ethanol at $48 \mathrm{~h}$, while MA-R4 produced no more than $15.3 \mathrm{~g} \mathrm{~L}^{-1}$. MA-R5 exhibited a 39\% higher xylose consumption rate and a 39\% higher ethanol production rate than MA-R4. These results suggest that protein-engineering of $\mathrm{XDH}$ is applicable to generate industrial recombinant $S$. cerevisiae capable to ferment both hexose and pentose at the same time.

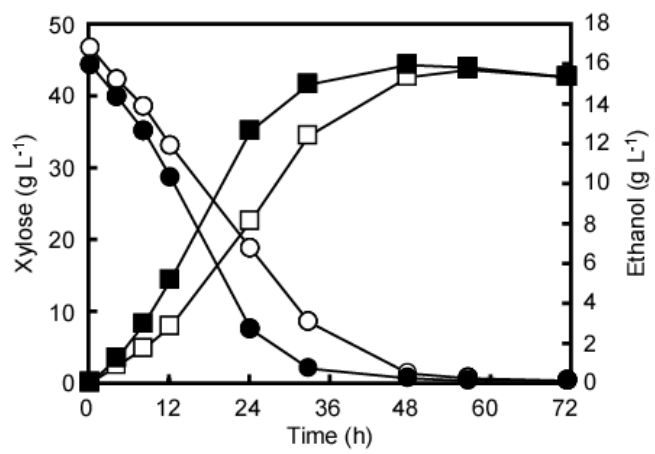

Xylose consumption (circles); ethanol production (squares).

Fig. 10. Xylose fermentation by recombinant S. cerevisiae, MA-R4 (open symbols) or MA-R5 (closed symbols).

\section{Conclusion}

A large body of literature has described the alteration of nicotinamide coenzyme specificity, by which several useful information have already been available. However, the full reversal of coenzyme specificity, in terms of having a mutant enzyme catalytically efficient as the wild type, has been rarely achieved. As illustrated in this chapter, in particular XDH, selection of reference enzyme with close phylogenetic relationship and continuous multiple site-directed mutagenesis including the known "landmark" amino acid residues were necessary for mutant design. Furthermore, it was shown that thermostabilization is dramatically achieved by carefully designed site-directed mutagenesis; introduction of metal ion and subsequently optimization of the binding region. These novel strategies would be very applicable for other dehydrogenase/reductase enzymes with Rossmann-fold type coenzyme-binding mode including a MDR superfamily.

Difference coenzyme specificity between $\mathrm{XDH}$ and $\mathrm{XR}$ is one of main factors for accumulating unfavourable by-product, xylitol, during xylose-fermentation by recombinant S. cerevisiae. In spite of this importance, a few approach based on protein-engineering have been reported for a long time. Recently, several metabolic engineering have been attempted to enhance the pentose-phosphate pathway and/or xylose-uptake; introduction and overexpression of other endogenous genes including xylulokinase $(\mathrm{XK})$, transketolase (TKL1), transaldolase (TAL1) and several hexose-transporter (HXT1-7) genes (Jeffries \& Jin, 2004). Combination of these approaches, the protein-engineered enzyme and useful industrial host strain (such as IR-2) should be considered to achieve more effective ethanol production from xylose by recombinant $S$. cerevisiae. 


\section{References}

Ammendola, S., Raia, C.A., Caruso, C., Camardella, L., D'Auria, S., De Rosa, M. \& Rossi, M. (1992). Thermostable $\mathrm{NAD}^{+}$-dependent alcohol dehydrogenase from Sulfolobus solfataricus. Gene and protein sequence determination and relationship to other alcohol dehydrogenases. Biochemistry, Vol.31, No.49, pp. 12514-12523, ISSN 00062960

Annaluru, N., Watanabe, S., Pack, S.P., Saleh, A.A., Kodaki, T. \& Makino, K. (2007). Thermostabilization of Pichia stipitis xylitol dehydrogenase by mutation of structural zinc binding loop. Journal of Biotechnology, Vol.129, No.4, pp. 717-722, ISSN 0168-1656

Baker, P.J., Britton, K.L., Rice, D.W., Rob, A. \& Stillman, T.J. (1992). Structural consequences of sequence patterns in the fingerprint region of the nucleotide binding fold. Implications for nucleotide specificity. Journal of Molecular Biology, Vol.228, No.2, pp. 662-671, ISSN 0022-2836

Banfield, M.J., Salvucci, M.E., Baker, E.N. \& Smith, C.A. (2001). Crystal structure of the $\mathrm{NADP}(\mathrm{H})$-dependent ketose reductase from Bemisia argentifolii at $2.3 \AA$ resolution. Journal of Molecular Biology, Vol.306, No.2, pp. 239-250, ISSN 0022-2836

Banta, S., Swanson, B.A., Wu, S., Jarnagin, A. \& Anderson, S. (2002). Alteration of the specificity of the cofactor-binding pocket of Corynebacterium 2,5-diketo-D-gluconic acid reductase A. Protein Enginerring, Vo.15, No.2, pp. 131-140, ISSN 0269-2139

Ellis, E.M. (2002). Microbial aldo-keto reductases. FEMS Microbiology Letters, Vo.216, No.2, pp. 123-131, ISSN 0378-1097

Jeffries, T.W. \& Jin, Y.S. (2004). Metabolic engineering for improved fermentation of pentoses by yeasts. Applied Microbiology and Biotechnology, Vol.63, No. 5, pp. 495509, ISSN 0175-7598

Jeloková, J., Karlsson, C., Estonius, M., Jornvall, H. \& Hoog, J.O. (1994). Features of structural zinc in mammalian alcohol dehydrogenase. Site-directed mutagenesis of the zinc ligands. Europian Journal of Biochemistry, Vol.225, No.3, pp. 1015-1019, ISSN 0014-2956

Kavanagh, K.L., Klimacek, M., Nidetzky, B. \& Wilson, D.K. (2002). The structure of apo and holo forms of xylose reductase, a dimeric aldo-keto reductase from Candida tenuis. Biochemistry, Vol.41, No. 28, pp. 8785-8795, ISSN 0006-2960

Kavanagh, K.L., Klimacek, M., Nidetzky, B. \& Wilson, D.K. (2003). Structure of xylose reductase bound to $\mathrm{NAD}^{+}$and the basis for single and dual co-substrate specificity in family 2 aldo-keto reductases. Biochemical Journal, Vol.373, No.2, pp. 319-326, ISSN 0264-6021

Lee, J., Koo, B. \& Kim, S. (2003). Cloning and characterization of the $x y l 1$ gene, encoding an NADH-preferring xylose reductase from Candida parapsilosis, and its functional expression in Candida tropicalis. Applied and Environmental Microbiology, Vol.69, No.10, pp. 6179-6188, ISSN 0099-2240

Magonet, E., Hayen, P., Delforge, D., Delaive, E. \& Remacle, J. (1992). Importance of the structural zinc atom for the stability of yeast alcohol dehydrogenase. Biochemical Journal, Vol.287, No.2, pp. 361-365, ISSN 0264-6021

Matsushika, A., Inoue, H., Watanabe, S., Kodaki, T., Makino, K. \& Sawayama, S. (2009). Efficient bioethanol production by recombinant flocculent Saccharomyces cerevisiae 
with genome-integrated $\mathrm{NADP}^{+}$-dependent xylitol dehydrogenase gene. Applied and Environmental Microbiology, Vol.75, No.11, pp. 3818-3822, ISSN 1098-5336

Matsushika, A., Watanabe, S., Kodaki, T., Makino, K., Inoue, H., Murakami, K. \& Sawayama, S. (2008a). Expression of protein engineered NADP+-dependent xylitol dehydrogenase increases ethanol production from xylose in recombinant Saccharomyces cerevisiae. Applied Microbiology and Biotechnology, Vo.81, No.2, pp. 243255, ISSN 1432-0614

Matsushika, A., Watanabe, S., Kodaki, T., Makino, K. \& Sawayama, S. (2008b). Bioethanol production from xylose by recombinant Saccharomyces cerevisiae expressing xylose reductase, $\mathrm{NADP}^{+}$-dependent xylitol dehydrogenase, and xylulokinase. Journal of Bioscience and Bioengineering, Vol.105, No.3, pp. 296-299, ISSN 1389-1723

Metzger, M.H. \& Hollenberg, C.P. (1995). Amino acid substitutions in the yeast Pichia stipitis xylitol dehydrogenase coenzyme-binding domain affect the coenzyme specificity. Europian Journal of Biochemistry, Vol.228, No.1, pp. 50-54, ISSN 0014-2956

Nordling, E., Jornvall, H. \& Persson, B. (2002). Medium-chain dehydrogenases/reductases (MDR). Family characterizations including genome comparisons and active site modelling. Europian Journal of Biochemistry, Vol.269, No.17, pp. 4267-4276, ISSN 0014-2956

Petschacher, B., Leitgeb, S., Kavanagh, K. L., Wilson, D. K. \& Nidetzky, B. (2005). The coenzyme specificity of Candida tenuis xylose reductase (AKR2B5) explored by sitedirected mutagenesis and X-ray crystallography. Biochemical Journal, Vol.385, No.1, pp. 75-83, ISSN 1470-8728

Petschacher, B. \& Nidetzky, B. (2005). Engineering Candida tenuis xylose reductase for improved utilization of NADH. Antagonistic effects of multiple side chain replacements and performance of site-directed mutants under simulated in vivo conditions. Applied and Environmental Microbiology, Vol.71, No.10, pp. 6390-6393, ISSN 0099-2240

Rosell, A., Valencia, E., Ochoa, W.F., Fita, I., Pares, X. \& Farres, J. (2003). Complete reversal of coenzyme specificity by concerted mutation of three consecutive residues in alcohol dehydrogenase. Journal of Biological Chemistry, Vol.278, No.42, pp. 4057340580, ISSN 0021-9258

Khattab, S.M., Watanabe, S., Saimura, M. \& Kodaki, T. (2011). A novel strictly NADPHdependent Pichia stipitis xylose reductase constructed by site-directed mutagenesis. Biochemical and Biophysical Research Communications, Vol.404, No.2, pp. 634-637, ISSN 1090-2104

Wang, J.C., Sakakibara, M., Matsuda, M. \& Itoh, N. (1999). Site-directed mutagenesis of two zinc-binding centers of the NADH-dependent phenylacetaldehyde reductase from styrene-assimilating Corynebacterium sp. strain ST-10. Bioscience, Biotechnology and Biochemistry, Vol.63, No.12, pp. 2216-2218, ISSN 0916-8451

Watanabe, S., Pack, S.P., Saleh, A.A., Pack, S.P., Annaluru, N., Kodaki, T. \& Makino, K. (2007a). The Positive effect of the decreased NADPH-preferring activity of xylose reductase from Pichia stipitis on the ethanol production using xylose-fermenting recombinant Saccharomyces cerevisiae. Bioscience, Biotechnology and Biochemistry, Vol.71, No.5, pp. 1365-1369, ISSN 0916-8451

Watanabe, S., Saleh, A.A., Pack, S.P., Annaluru, N., Kodaki, T. \& Makino, K. (2007b). Ethanol production from xylose by recombinant Saccharomyces cerevisiae expressing 
protein engineered $\mathrm{NADP}^{+}$-dependent xylitol dehydrogenase. Journal of Biotechnology, Vol.130, No.3, pp. 316-319, ISSN 0168-1656

Watanabe, S., Saleh, A.A., Pack, S.P., Annaluru, N., Kodaki, T. \& Makino, K. (2007c). Protein engineering of xylose reductase from Pichia stipitis for improved NADH-specificity and the efficient ethanol production from xylose in recombinant Saccharomyces cerevisiae. Microbiology, Vol.153, No.9, pp. 3045-3055, ISSN 1350-0872

Watanabe, S., Kodaki, T. \& Makino, K. (2005). Complete reversal of coenzyme specificity of xylitol dehydrogenase and increase of thermostability by the introduction of structural zinc. Journal of Biological Chemistry Vol.280, No.11, pp. 10340-10349, ISSN 0021-9258 


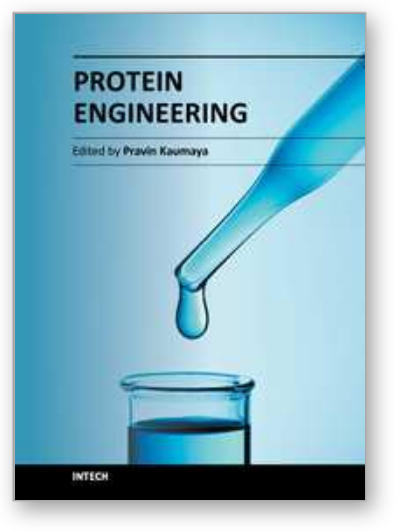

\author{
Protein Engineering \\ Edited by Prof. Pravin Kaumaya
}

ISBN 978-953-51-0037-9

Hard cover, 344 pages

Publisher InTech

Published online 24, February, 2012

Published in print edition February, 2012

\begin{abstract}
A broad range of topics are covered by providing a solid foundation in protein engineering and supplies readers with knowledge essential to the design and production of proteins. This volume presents in-depth discussions of various methods for protein engineering featuring contributions from leading experts from different counties. A broad series of articles covering significant aspects of methods and applications in the design of novel proteins with different functions are presented. These include the use of non-natural amino acids, bioinformatics, molecular evolution, protein folding and structure-functional insight to develop useful proteins with enhanced properties.
\end{abstract}

\title{
How to reference
}

In order to correctly reference this scholarly work, feel free to copy and paste the following:

Seiya Watanabe and Keisuke Makino (2012). Generation of Xylose-Fermenting Saccharomyces Cerevisiae by Protein-Engineering, Protein Engineering, Prof. Pravin Kaumaya (Ed.), ISBN: 978-953-51-0037-9, InTech, Available from: http://www.intechopen.com/books/protein-engineering/generation-of-xylose-fermentingsaccharomyces-cerevisiae-by-protein-engineering

\section{INTECH}

open science | open minds

\section{InTech Europe}

University Campus STeP Ri Slavka Krautzeka 83/A 51000 Rijeka, Croatia Phone: +385 (51) 770447 Fax: +385 (51) 686166 www.intechopen.com

\section{InTech China}

Unit 405, Office Block, Hotel Equatorial Shanghai No.65, Yan An Road (West), Shanghai, 200040, China 中国上海市延安西路65号上海国际贵都大饭店办公楼405单元 Phone: +86-21-62489820

Fax: +86-21-62489821 
(C) 2012 The Author(s). Licensee IntechOpen. This is an open access article distributed under the terms of the Creative Commons Attribution 3.0 License, which permits unrestricted use, distribution, and reproduction in any medium, provided the original work is properly cited. 